\title{
Clinical Safety and Efficacy of Platelet-Rich Plasma in Wound Healing
}

\author{
Samir M. Ghoraba, Wael H. Mahmoud*, Said M. Hammad, Hashem M. Ayad \\ Plastic, Reconstructive Surgery and Burns Department, Tanta Faculty of Medicine, Tanta, Egypt \\ Email: *waelhussein_558@yahoo.com
}

How to cite this paper: Ghoraba, S.M., Mahmoud, W.H., Hammad, S.M. and Ayad, H.M. (2016) Clinical Safety and Efficacy of Platelet-Rich Plasma in Wound Healing. International Journal of Clinical Medicine, 7, 801-808.

http://dx.doi.org/10.4236/ijcm.2016.712086

Received: September 15, 2016

Accepted: November 27, 2016

Published: November 30, 2016

Copyright $\odot 2016$ by authors and Scientific Research Publishing Inc. This work is licensed under the Creative Commons Attribution International License (CC BY 4.0).

http://creativecommons.org/licenses/by/4.0/

Open Access

\begin{abstract}
Background: Platelet-rich plasma has been extensively used in several clinical settings. However, there still a lack of conclusive evidence concerning the benefits of platelet-rich plasma in the field of wound healing. We aimed to evaluate the safety and the efficacy of autologous platelet-rich plasma in acute wound healing. Methods: This prospective study enrolled forty adult patients of both sexes and aged between 18 - 50 years. All patients in need for split-thickness skin graft were included in our study. The donor sites were randomly divided into two equal halves: the platelet-rich plasma side, which was injected with recently activated platelet-rich plasma; and the control side, in which the conventional method of dressing was used. Measurement of the platelet count and transforming growth factor-B1 concentration in each platelet-rich plasma preparation and the whole blood was done for all patients. Clinical monitoring of the donor sites was done every 7 days for 3 weeks, regarding pain perception, epithelialization surface area and possible side effects of the platelet-rich plasma. Histopathological monitoring was done on the $7^{\text {th }}$ postoperative day. Results: The platelet count was increased about 3.5 folds and transforming growth factor-B1 was increased 2.4 folds in the platelet-rich plasma compared to the patients' blood. The platelet-rich plasma side had significantly lower pain scores at day 7 (4.8 \pm 0.18 vs $5.9 \pm 0.07)$ and day $14(1.4 \pm 0.11$ vs $1.9 \pm 0.09)$ postoperative $(p=0.002$ and $p=$ 0.004 , respectively) and had significantly higher rate of epithelialization at day 7 (9.8 \pm $0.35 \mathrm{~cm}^{2}$ vs $\left.7.5 \pm 0.32 \mathrm{~cm}^{2}\right)$ and day $14\left(38.4 \pm 0.36 \mathrm{~cm}^{2}\right.$ vs $\left.36.9 \pm 0.42 \mathrm{~cm}^{2}\right)$ postoperative ( $p<0.001$ and $p=0.039$, respectively), while at day 21 postoperative, there was no significant difference between both sides. There was no significant difference between both sides regarding the incidence of complications. The platelet-rich plasma side showed intact epithelium, differentiation of the cells in stratum spongiosum and stratum granulosum, neovascularization and earlier collagen deposition. Conclusion: The platelet-rich plasma is safe and effective adjuvant in the management of acute wounds. However, we recommend for larger clinical trials for standardized method for PRP preparation and better understanding of the efficacy of this blood product.
\end{abstract}




\section{Keywords}

Platelet-Rich Plasma (PRP), Wound Healing, Acute Wounds

\section{Introduction}

Wound healing is a dynamic and complex process controlled by interacting signals that regulate a myriad of cellular and molecular events. Therefore, no single agent can efficiently mediate all aspects of the wound healing process [1]. Platelets not only assist in clot formation, but also are a rich source of a host of growth factors and cytokines essential to wound healing [2]. Platelets activation by proteins as thrombin causes the $\alpha$-granules to fuse with the platelet cell membrane releasing these growth factors, such as transforming growth factor-b (TGF-b), platelet-derived growth factor (PDGF), vascular endothelial growth factor (VEGF), epidermal growth factor (EGF), fibroblast growth factor (FGF) and insulin-like growth factor (IGF) [3]. These growth factors are crucial in attraction of mesenchymal cells into the wound, enhancing their proliferation and promoting extracellular matrix deposition during the healing process [4].

When the natural healing process becomes interrupted by either wound factors (i.e. infection) or patient factors (i.e. comorbidities), the standard wound care is not enough to improve the healing outcome and advanced therapeutic modalities are always required, such as negative pressure therapy, hyperbaric oxygen therapy, low level laser therapy, growth factors and platelet-rich plasma (PRP) [5] [6]. Platelet-rich plasma is a blood derivative that contains a higher concentration of platelets, about 3 to 5 times the normal value [7]. PRP also contains a variable number of white blood cells and red blood cells according to the preparation method [8].

PRP mechanism of action is still questionable; however, it may act by enhancing the natural healing process, as the molecules contained within the PRP preparation act as adjuvant in the inflammatory and proliferative phases [9]. Although PRP applications are now widely used in many medical fields, including orthopedics, maxillofacial surgery, cardiothoracic surgery, plastic surgery, trauma surgery and wound healing, their efficacy in human subjects is still debated [10]. We aimed in this study to evaluate the safety and the efficacy of autologous platelet-rich plasma (PRP) as an aid in the healing process of acute wounds; the donor site of the split-thickness skin graft (STSG) was used as a model of acute wounds.

\section{Materials and Methods}

This prospective study enrolled forty adult patients, of both sexes (28 males and $12 \mathrm{fe}$ males), aged between 18 - 50 years (mean-28.6 years), who were admitted to the Plastic Surgery Department, Tanta University Hospitals between August 2013 and August 2015. All patients had post-traumatic raw areas and were in need for STSG obtained from the thigh were included in our study. Patients with chronic diseases such as hepatic insufficiency and diabetes, those on steroids or immunosuppressive therapy, or 
those with blood and collagen diseases as well as smokers were excluded from the study. All materials and procedures were approved by the Ethics Committee of the University. Informed consent was obtained, after detailed description of the procedure, from all patients.

\subsection{Preparation of Platelet-Rich Plasma (PRP)}

Before the surgical phase, $50 \mathrm{ml}$ of the autologous venous blood was withdrawn from every patient and collected in a sterile tube containing $5 \mathrm{ml}$ of citrate phosphate dextrose (CPD) as anticoagulant. The blood sample was centrifuged at room temperature for $5 \mathrm{~min}$ at 2500 r.p.m in the centrifuge machine (eppendorf centrifuge 5804). After the $1^{\text {st }}$ centrifugation, the blood was separated in red blood cells and plasma. The red cells were removed, and the remaining plasma was centrifuged at 3500 r.p.m for $5 \mathrm{~min}$. After the $2^{\text {nd }}$ centrifugation, the centrifuge was separated into platelet-rich plasma (PRP) at the bottom layer; constituting $10 \%$ of the withdrawn blood volume and platelet-poor plasma (PPP) at the upper layer. Measurement of the platelet count and the transforming growth factor-B1 concentration using the DRG TGF-B1 ELISA kit in each PRP preparation and the whole blood were done for all patients.

\subsection{Surgical Procedure}

All surgical procedures were done under general anaesthesia. A STSG was harvested from the thigh using the Humby's Knife. The donor sites were randomly divided into two equal halfs: the PRP side, which was injected with recently activated PRP by mixing with $2 \%$ calcium chloride at a ratio $7: 1$; and the control side, in which the conventional method of dressing was used. Vaselinized gauze and secondary absorbant layer dressing were used to cover the donor sites in all patients. The time needed from preparation till injection of the activated PRP was recorded for all patients.

\subsection{Postoperative Care and Monitoring}

All patients were discharged on the $2^{\text {nd }}$ postoperative day and recalled again once weekly for one month and once monthly for 3 months. Clinical monitoring of the donor sites was done every 7 days for 3 weeks, regarding pain perception, epithelialization surface area and possible side effects of the PRP (reaction to PRP-infection-hypertrophic scar-hyperpigmentation). The pain was measured using the visual analogue scale (0 10). Histopathological monitoring was done on the $7^{\text {th }}$ postoperative day. Under local anaesthesia ( $0.5 \%$ xylocaine), a 3-mm punch biopsy was taken from the PRP and the control sides then fixed with $10 \%$ paraformaldehyde. The paraffin fixed specimens were stained using the H\&E stain. Thereafter, examination of the specimen was done regarding keratin formation, epidermal thickening, infiltration of the dermis with inflammatory cells, neovascularization and collagen deposition.

The data collected for statistical analysis were expressed as means and standard error of the means (SEM). Student's t-test and Chi-square test were used for comparative analysis. Statistical significance was defined as $p$ value of $<0.05$. 


\section{Results}

Over a two-year period, forty patients subjected to STSG and PRP application to one half of the donor site. As shown in Table 1, there were significant increase in the mean concentrations of the platelets and TGF-B1 in the PRP compared to the patients' blood $(p<0.001)$, with the platelets being about 3.5-fold higher, and TGF-B1 about 2.4-fold higher, than in the serum. The time needed from preparation till injection of the activated PRP ranged from 45 to $82 \mathrm{~min}$ (mean-68.3 min).

Table 2 shows that, there was no significant difference between the PRP side and the control side in the pain scores at day 0 and day 21 postoperative, but the PRP side had significantly lower pain scores at days 7 and 14 postoperative $(p=0.002$ and $p=0.004$ respectively). Furthermore, there was improvement in the wound healing in the PRP side as evident by the significant increase in the epithelialization surface area in the PRP side at days 7 and 14 postoperative ( $p<0.001$ and $p=0.039$ respectively), while at day 21 postoperative there was no significant difference between both sides. One patient had infection and another developed hypertrophic scar at both sides, while two patients had hyperpigmentation and hypertrophic scar at the PRP side only. There was no significant difference between both sides regarding the incidence of complications.

As regards histopathological monitoring, the PRP side (Figure 1) showed differentiation of the epidermal keratinocytes with intact epithelium, differentiation of the cells in stratum spongiosum and stratum granulosum, neovascularization and beginning of collagen deposition, while the control side (Figure 2) showed minimal epithelial covering with extensive areas of ulceration, edema below the epidermis with extensive perivascular inflammatory infiltrate with acute inflammatory cells mainly neutrophils, undifferentiated keratinocytes in stratum spongiosum and stratum granulosum and minimal collagen deposition.

Table 1. Laboratory data (mean \pm SEM).

\begin{tabular}{cccc}
\hline Variable & Patient's blood & PRP & $p$ value \\
\hline Platelets count $\left(\right.$ cell $\left./ \mathrm{mm}^{3}\right)$ & $210.250 \pm 9.38$ & $742.450 \pm 36.68$ & $<0.001$ \\
TGF-B1 concentration $(\mathrm{ng} / \mathrm{dl})$ & $670.0 \pm 27.94$ & $1650.0 \pm 65.52$ & $<0.001$ \\
\hline
\end{tabular}

Table 2. Outcome clinical data.

\begin{tabular}{cccc}
\hline Variable & PRP side $(\mathbf{n}=40)$ & Control side $(\mathbf{n}=40)$ & $p$ value \\
\hline Pain scores $^{\mathrm{a}}$ & & & \\
Day 0 & $7.9 \pm 0.17$ & $8.2 \pm 0.19$ & NS \\
Day 7 & $4.8 \pm 0.18$ & $5.9 \pm 0.07$ & 0.002 \\
Day 14 & $1.4 \pm 0.11$ & $1.9 \pm 0.09$ & 0.004 \\
Day 21 & $0.6 \pm 0.13$ & $0.8 \pm 0.11$ & NS \\
Epithelialization surface area $\left(\mathrm{cm}^{2}\right)^{\mathrm{b}}$ & & & \\
Day 7 & $9.8 \pm 0.35$ & $7.5 \pm 0.32$ & $<0.001$ \\
Day 14 & $38.4 \pm 0.36$ & $36.9 \pm 0.42$ & 0.039 \\
Day 21 & $86.3 \pm 0.66$ & $85.8 \pm 0.68$ & NS \\
Complications (n. \%) & $4(10 \%)$ & $2(5 \%)$ & NS \\
\hline
\end{tabular}

${ }^{\mathrm{a}, \mathrm{b}}$ Mean \pm SEM. 


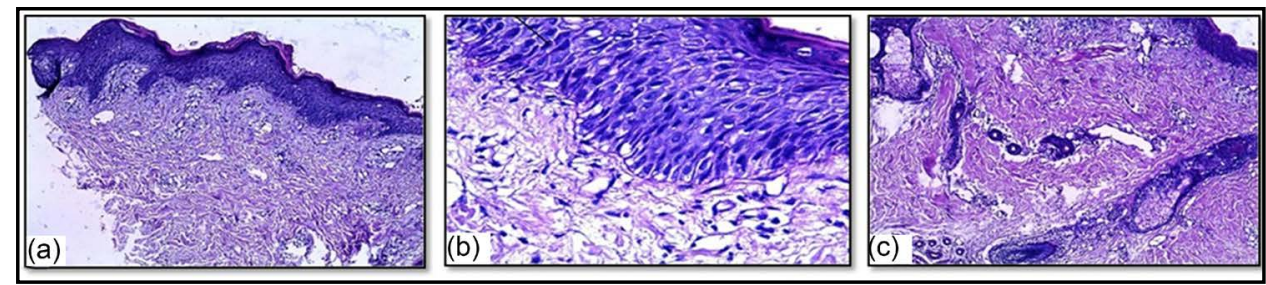

Figure 1. Light micrograph of PRP side at day 7 using H\&E stain. (a) Regenerated intact epithelium with differentiated epidermal keratinocyes $(\times 100)$; (b) Differentiated polyhydral cells in stratum spongiosum and cells in stratum granulosum $(\times 400)$; (c) Collagen deposition with minimal infiltration of inflammatory cells $(\times 200)$.

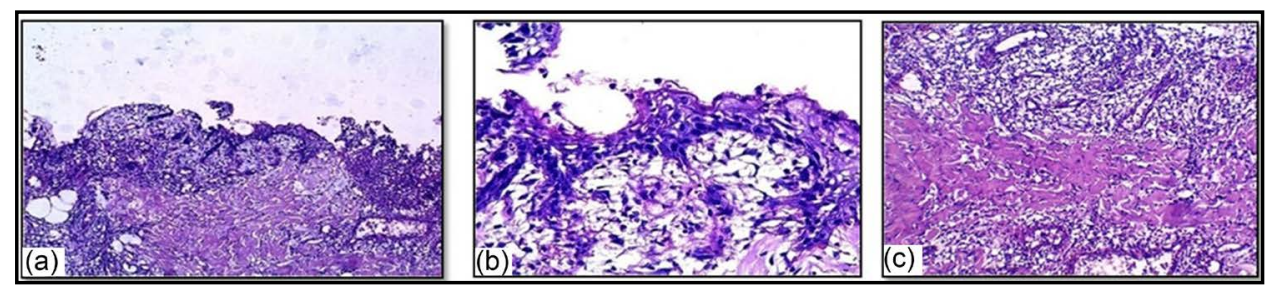

Figure 2. Light micrograph of control side at day 7 using H\&E stain. (a) Minimal and partial epithelial covering with extensive areas of ulceration $(\times 100)$; (b) Thin epidermal covering in high power field $(\times 400)$; (c) Extensive perivascular inflammatory infiltrate and minimal collagen deposition $(\times 200)$.

\section{Discussion}

Platelet-rich plasma (PRP) has been largely used in several clinical settings. Moreover, it is considered to promote tissue regeneration due to presence of growth factors and essential cytokines. Nevertheless, many studies fail to deliver conclusive evidence concerning the benefits of PRP in the field of wound healing. This study was undertaken to evaluate the safety and the efficacy of autologus platelet-rich plasma (PRP) in acute wound healing.

In our study, we chose the donor sites of STSGs as model of acute wounds. Similarly, Danielsen et al. [11] tested the effect of PRP on the epithelialization of the donor sites of STSGs. In other studies, Hom et al. [12] and Kazakos et al. [3] evaluated the effect of PRP on full thickness skin punch wounds and acute traumatic wounds as open fracture tibia respectively.

Sommeling et al. [13] in their systematic review of 15 randomised controlled trials and 25 case control studies found that there is no standard technique of PRP preparation. In this study, we adapted the double spin technique and observed that the platelet count was increased about 3.5 folds and TGF-B1 was increased 2.4 folds. In a similar study, Marukawa et al. [14] used the double spin technique for PRP preparation and noticed that the platelet count was increased about 3 times and the platelet released growth factors increased about 2 - 3 times. Conversely, Pietrzak et al. [15] suggested that a four to five fold increase in the baseline of platelet count is needed but they show no clear evidence that lower or higher concentration may decrease or increase the positive effect of PRP. 
We found that the mean time needed from preparation till injection of the activated PRP was $68.3 \mathrm{~min}$. Unlike us, Kazakos et al. [3] reported a relatively shorter time (mean-52 min), which could be attributed to the single centrifugation protocol adapted by them. This series witnessed improvement in the wound healing in the PRP side as evident by the significant increase in the epithelialization surface area in the PRP side at days 7 and 14 postoperative ( $p<0.001$ and $p=0.039$ respectively). Similar to our study and findings, Kakudo et al. [16] studied the effect of PRP on the donor site of STSG and noticed macroscopic epithelialization on the $5^{\text {th }}$ day of PRP application. In another study, Spyridakis et al. [17] noted that complete wound closure was statistically faster in the PRP treated wounds. Contrary to our results, Danielsen et al. [11] observed no significant difference in the macroscopic epithelialization between PRP and control groups in their study.

In our series, the pain scores, while not differing at day 0 and 21 postoperative, significantly decreased by day 7 and 14 postoperative in the PRP side compared to the control side ( $p=0.002$ and $p=0.004$ respectively). In similar studies, Englert et al. [18] found that postoperative pain was significantly reduced for the PRP treated wounds and Khalifi et al. [19] observed that intravenous narcotic use was statistically lower in the PRP treated subjects. In another study, Kazakos et al. [3] noticed that there was no pain difference between both groups at the end of the $1^{\text {st }}$ week, while there was lower pain scores in the PRP treated group at the end of the $2^{\text {nd }}$ week.

This study demonstrated that the PRP side exhibits intact epithelium with thicker epidermis, differentiated epidermal keratinocytes, neovascularization and beginning of collagen deposition. These data are in accordance with that of Hom et al. [12], who reported thicker epidermis at the $7^{\text {th }}$ day of PRP application to acute wounds and Marx et al. [20], who noticed thicker epithelium and newly formed blood vessels in the PRP side. In experimental study, Carter et al. [21] tested the effect of PRP gel on equine wounds and observed that PRP gel induced accelerated epithelial differentiation and early collagen deposition.

We observed that there was no significant difference between both sides regarding the incidence of complications which is consistent with Wang-Saegusa et al. [22] who studied the effect of PRP injection into the knee joint of over 800 patients and noticed no adverse effects, and is also consistent with Mazzucco et al. [23] who used PRP gel to treat heal wounds and reported no serious adverse events. Moreover, Powell et al. [24] demonstrated that wound treatment with PRP gel can reduce the incidence of ecchymosis and the formation of edema. In our point of view, the small sample size and the single injection time are the main limitations of our study.

\section{Conclusion}

We can conclude that the platelet-rich plasma is safe and effective adjuvant in the management of acute wounds. However, we recommend for larger clinical trials for standardized method for PRP preparation and better understanding of the efficacy and the safety of this blood product. 


\section{References}

[1] Gharaee-Kermani, M. and Phan, S.H. (2001) Role of Cytokines and Cytokine Therapy in Wound Healing and Fibrotic Diseases. Current Pharmaceutical Design, 7, 1083-1103. http://dx.doi.org/10.2174/1381612013397573

[2] Dugrillon, A. and Kluter, H. (2002) Current Use of Platelet Concentrates for Topical Application in Tissue Repair. Infusion Therapy and Transfusion Medicine, 29, 67-70.

[3] Kazakos, K., Lyras, D.N., Verettas, D., Tilkeridis, K. and Tryfonidis, M. (2009) The Use of Autologous PRP Gel as an Aid in the Management of Acute Trauma Wounds. Injury, 40, 801-805. http://dx.doi.org/10.1016/j.injury.2008.05.002

[4] Yuan, T., Zhang, C.Q., Tang, M.J., Guo, S.C. and Zeng, B.F. (2009) Autologous PlateletRich Plasma Enhances Healing of Chronic Wounds. Wounds, 21, 280-285.

[5] Kumar, S., Wong, P.F. and Leaper, D.J. (2004) What Is New in Wound Healing? Turkish Journal of Medical Sciences, 34, 147-160.

[6] Carter, M.J., Fylling, C.P. and Parnell, L.K. (2011) Use of Platelet Rich Plasma Gel on Wound Healing: A Systematic Review and Meta-Analysis. Eplasty, 11, 382-410.

[7] Marx, R.E. (2001) Platelet-Rich Plasma (PRP): What Is PRP and What Is Not PRP? Implant Dentistry, 10, 225-228. http://dx.doi.org/10.1097/00008505-200110000-00002

[8] Castillo, T.N., Pouliot, M.A., Kim, H.J. and Dragoo, J.L. (2011) Comparison of Growth Factor and Platelet Concentration from Commercial Platelet-Rich Plasma Separation Systems. American Journal of Sports Medicine, 39, 266-271. http://dx.doi.org/10.1177/0363546510387517

[9] Andia, I., Sánchez, M. and Maffulli, N. (2012) Joint Pathology and Platelet-Rich Plasma Therapies. Expert Opinion on Biological Therapy, 12, 7-22. http://dx.doi.org/10.1517/14712598.2012.632765

[10] Papalia, R., Vasta, S., Zampogna, B., Tecame, A., Maffulli, N. and Denaro, V. (2012) Platelet-Rich Plasma Injections and Surgery: Short-Term Outcomes and Long-Term Prognosis. Operative Techniques in Orthopaedics, 22, 71-77. http://dx.doi.org/10.1053/j.oto.2012.01.001

[11] Danielsen, P., Jorgensen, B., Karlsmark, T., Jorgensen, L.N. and Agren, M.S. (2008) Effect of Topical Autologous Platelet-Rich Fibrin versus No Intervention on Epithelialization of Donor Sites and Meshed Split-Thickness Skin Autografts: A Randomized Clinical Trial. Plastic and Reconstructive Surgery, 122, 1431-1440. http://dx.doi.org/10.1097/PRS.0b013e318188202c

[12] Hom, D.B., Linzie, B.M. and Huang, T.C. (2007) The Healing Effects of Autologous Platelet Gel on Acute Human Skin Wounds. Archives of Facial Plastic Surgery, 9, 174-183. http://dx.doi.org/10.1001/archfaci.9.3.174

[13] Sommeling, C.E., Heyneman, A., Hoeksema, H., Verbelen, J., Stillaert, F.B. and Monstrey, S. (2013) The Use of Platelet-Rich Plasma in Plastic Surgery: A Systematic Review. Journal of Plastic, Reconstructive \& Aesthetic Surgery, 66, 301-312. http://dx.doi.org/10.1016/j.bjps.2012.11.009

[14] Marukawa, E., Oshina, H., Iino, G., Morita, K. and Omura, K. (2011) Reduction of Bone Resorption by the Application of Platelet-Rich Plasma (PRP) in Bone Grafting of the Alveolar Cleft. Journal of Cranio-Maxillo-Facial Surgery, 39, 278-283. http://dx.doi.org/10.1016/j.jcms.2010.04.017

[15] Pietrzak, W. and Eppley, B. (2005) Platelet Rich Plasma: Biology and New Technology. Journal of Craniofacial Surgery, 16, 1043-1054. http://dx.doi.org/10.1097/01.scs.0000186454.07097.bf 
[16] Kakudo, N., Kushida, S. and Minakata, T. (2011) Platelet-Rich Plasma Promotes Epithelialization and Angiogenesis in a Split Thickness Skin Graft Donor Site. Medical Molecular Morphology, 44, 233-236. http://dx.doi.org/10.1007/s00795-010-0532-1

[17] Spyridakis, M., Christodoulidis, G., Chatzitheofilou, C., Symeonidis, D. and Tepetes, K. (2009) The Role of the Platelet-Rich Plasma in Accelerating the Wound-Healing Process and Recovery in Patients Being Operated for Pilonidal Sinus Disease: Preliminary Results. World Journal of Surgery, 33, 1764-1769. http://dx.doi.org/10.1007/s00268-009-0046-y

[18] Englert, S.J., Estep, T.H. and Ellis-Stoll, C.C. (2008) Postoperative Surgical Chest and Leg Incision Sites Using Platelet Gel: A Retrospective Study. Journal of Extra-Corporeal Technology, 40, 225-228.

[19] Gardner, M.J., Demetrakopoulos, D., Klepchick, P.R. and Mooar, P.A. (2007) The Efficacy of Autologous Platelet Gel in Pain Control and Blood Loss in Total Knee Arthroplasty. An Analysis of the Haemoglobin, Narcotic Requirement and Range of Motion. International Orthopaedics, 31, 309-313. http://dx.doi.org/10.1007/s00264-006-0174-Z

[20] Marx, R.E. (2004) Platelet-Rich Plasma: Evidence to Support Its Use. Journal of Oral and Maxillofacial Surgery, 62, 489-496. http://dx.doi.org/10.1016/j.joms.2003.12.003

[21] Carter, C.A., Jolly, D.G., Worden, C.E., Hendren, D.G. and Kane, C.J. (2003) Platelet-Rich Plasma Gel Promotes Differentiation and Regeneration during Equine Wound Healing. Experimental and Molecular Pathology, 74, 244-255. http://dx.doi.org/10.1016/S0014-4800(03)00017-0

[22] Wang-Saegusa, A., Cugat, R., Ares, O., Seijas, R., Cuscó, X. and Garcia-Balletbó, M. (2011) Infiltration of Plasma Rich in Growth Factors for Osteoarthritis of the Knee Short-Term Effects on Function and Quality of Life. Archives of Orthopaedic and Trauma Surgery, 105, 311-317. http://dx.doi.org/10.1007/s00402-010-1167-3

[23] Mazzucco, L., Medici, D., Serra, M., Panizza, R., Rivara, G., Orecchia, S., Libener, R., Cattana, E., Levis, A., Betta, P.G. and Borzini, P. (2004) The Use of Autologous Platelet Gel to Treat Difficult-to-Heal Wounds: A Pilot Study. Transfusion, 44, 1013-1018. http://dx.doi.org/10.1111/j.1537-2995.2004.03366.x

[24] Powell, D.M., Chang, E. and Farrior, E.H. (2001) Recovery from Deep-Plane Rhytidectomy Following Unilateral Wound Treatment with Autologous Platelet Gel: A Pilot Study. Archives of Facial Plastic Surgery, 3, 245-250. http://dx.doi.org/10.1001/archfaci.3.4.245

\section{Submit or recommend next manuscript to SCIRP and we will provide best service for you:}

Accepting pre-submission inquiries through Email, Facebook, LinkedIn, Twitter, etc.

A wide selection of journals (inclusive of 9 subjects, more than 200 journals)

Providing 24-hour high-quality service

User-friendly online submission system

Fair and swift peer-review system

Efficient typesetting and proofreading procedure

Display of the result of downloads and visits, as well as the number of cited articles

Maximum dissemination of your research work

Submit your manuscript at: http://papersubmission.scirp.org/

Or contact ijcm@scirp.org 